\title{
PRÁTICAS DE CUIDADO NÃO-MÉDICAS: TENSÃO, OPOSIÇÃO OU INTEGRAÇÃO?
}

\section{NON-MEDICAL HEALTHCARE: TENSION, OPPOSITION OR INTEGRATION?}

\author{
Daniela Maria Barreto Martins', Paulo Henrique Novaes Martins² \\ Autora para correspondência: Daniela Maria Barreto Martins - dabamartins@yahoo.com.br \\ 'Psicóloga, Doutora em Sociologia pela Universidade Federal de Pernambuco, Professora da Universidade do Estado da Bahia. \\ Salvador, Bahia, Brasil. \\ ${ }^{2}$ Doutor em Sociologia. Professor na Universidade Federal de Pernambuco. Recife, Pernambuco, Brasil.
}

RESUMO I A desabilitação de práticas populares de cura, a partir de mecanismos de desqualificação e de hostilidade ao não-científico é reconhecida historicamente como fenômeno associado à força do estabelecimento da medicina científica como grande e único discurso/prática possível para o cuidado em Saúde. Este debate é reaquecido na presença das terapias integrativas atuais, que reinserem muitas destas práticas outrora negadas em experiências de cuidado e de cura, cuja adesão e aceitação vêm crescendo significativamente na atualidade. Pretende-se neste artigo compreender a partir de quais movimentos tais práticas se firmaram na atualidade, não necessariamente como fenômenos externos ou agenciamentos isolados ("invisíveis"), mas, progressivamente reconhecidos em suas potencialidades. Para tal, são analisadas as expressões "Alternativo", "Holístico", "Complementar" e "Integrativo", destacando as tensões, oposições e integrações neste campo de co-existências entre práticas médicas e não-médicas. As análises empreendidas neste trabalho têm caráter históricoanalítico e foram realizadas a partir de investigações teóricas e revisões de literatura com fontes secundárias e guias de referência.

Palavras-chave: Terapias Complementares, Integralidade em Saúde, Humanização da Assistência.

\begin{abstract}
The disabling of popular healing practices due to disqualification and hostility mechanisns is historically recognized as a phenomenon associated with the strength of the establishment of scientific medicine as the unique reliable discourse / practice for health care. This debate has been revisited due to the presence of current integrative therapies that reinserted many of these practices once denied in experiences of care and healing, such as adherence and acceptance, growing significantly nowadays. This paper argues that these movements and practices are currently widespread and cannot be understood as external phenomena or isolated assemblages, but as progressively recognized healing practices due to their potentialities. To that end, they are analyzed as "Alternative", "Holistic", "Complementary" and "Integrative", stressing as tensions, oppositions and integrations in this field of coexistence between medical and non-medical practices. As analyzes carried out in this work, the historical-analytical character was carried out from theoretical investigations and literature reviews with secondary sources and reference guides.
\end{abstract}

Key-Words: Integrality in Health, Complementary Therapies, Humanization of Assistance 
De acordo com Pimenta (1998), diversas práticas de cuidado e cura já estiveram em uma relação de coexistência de forma relativamente pacífica e mutuamente aceitável nos idos no Brasil oitocentista. Embora não se pudesse observar uma consistente estruturação da medicina acadêmica àquela época, era destacável a aceitação, reconhecimento e regulamentação de práticas de cura populares por um órgão oficial de Portugal, conhecido como Fisicatura-mor.

A Fisicatura-mor se instala no Brasil Colônia e é extinta por volta de 1828, com a criação das Escolas de Medicina na Bahia e do Rio de Janeiro, consideradas marcos históricos da profissionalização médica no Brasil (PIMENTA, 1998). Este órgão tinha como função fiscalizar e regulamentar as práticas conhecidas como "artes de cura" e expedia licenças e cartas para dar autorização ao exercício de atividades de Médico, Boticário, Cirurgião, Sangrador, Partejador e Curandeiro. Embora mencione que há muito menor prestígio para as atividades exercidas por classes menos privilegiadas, como Sangradores, Curandeiros e Parteiras - práticas usualmente destinadas a escravos, forros e mulheres -, Pimenta (1998) chama a atenção para o fato de que os registros encontrados nos documentos da Fisicatura-mor evidenciam uma relação de complementaridade e divisão de tarefas na promoção da saúde jamais observadas depois da regulamentação da profissão médica no Brasil. Conforme analisa em seu estudo sobre estes registros históricos:

A Fisicatura-mor era instituição de uma sociedade na qual as relações sociais baseavam-se na construção e na reafirmação de dependências pessoais. A hierarquia social era reafirmada com a troca de favores, e benefícios por lealdade e obediência. E o modo como funcionava a Fisicatura-mor também fortalecia e deixava evidente essa hierarquia. [...]

Os médicos, cirurgiões e boticários consideravam o seu saber superior ao dos terapeutas populares, mas não os desqualificavam totalmente, pois o conhecimento destes sobre a natureza da região era valorizado. Durante o período de existência da Fisicatura-mor, o contexto não era de medicalização da sociedade, de imposição de padrões científicos, de higienização das cidades, de modificação e normalização de condutas, o que torna a documentação da Fisicatura-mor mais importante, vez que, depois de seu término, não se tem notícia de outro qualquer órgão público que tivesse o objetivo de fiscalizar e autorizar práticas médicas as mais variadas, registrando assim práticas populares de cura. (PIMENTA, 1998, p.351).

É importante ainda mencionar as suas observações acerca das formas como as práticas populares se mantinham e gozavam de reconhecimento e prestígio nos grupos sociais em que atuavam (muitas vezes independente da regulamentação da Fisicatura-mor, já que o seu alcance era limitado), considerando-se aí a disseminação e a popularidade destas práticas. Através destes registros, a autora constata que, muitas vezes, o reconhecimento e a regulamentação destas práticas ocorriam por via de solicitações (abaixo-assinados) dos grupos sociais em que o terapeuta popular atuava. Em suas análises, ainda associa este prestígio do terapeuta ao fato de sua abordagem da doença contemplar explicações mais afinadas com a visão daquelas pessoas, sobretudo no que diz respeito às dimensões espirituais associadas às enfermidades.

A efetividade dos agentes populares, conclui a autora, seja pelo vasto conhecimento de tratamentos eficazes ou pela atenção dada tanto a problemas físicos quanto espirituais, era a contrapartida das limitações das práticas médicas. Esta situação irá mudar radicalmente algumas décadas mais tarde com a criação das escolas de medicina. Observouse aí a expressão de uma hostilidade crescente aos sistemas de cura populares: o que era considerado complementar, passava a representar uma ameaça, situação em que se impõem veementemente os padrões da aspirante medicina científica.

De forma semelhante, Loyola (1984) demonstrou, em suas pesquisas, prestígios diferenciados, gozados pelos especialistas de cura perante sua clientela. A tipologia trabalhada pela autora diferenciou os especialistas de tal modo, que revelou uma multiplicidade de agentes no bairro de Santa Rita, Nova Iguaçu-RJ. A proximidade e afinidade entre agentes de cura (divididos entre cuidados do corpo e cuidados do espírito) e clientes reafirmaram as análises que apontavam 0 proveito do prestígio da clientela no trabalho dos agentes populares. Contudo, mereceram destaque suas observações acerca dos "médicos populares" e da "medicina tradicional popular" (LOYOLA, 1984, p. 126). 
Conforme a autora, os médicos populares eram, em sua maioria, oriundos de classes populares, nascidos ou há muito tempo residentes no bairro. Muitas vezes eram filhos de curandeiros de muita influência no local. A sua posição era particularmente especial, pois exerciam uma espécie de intermediação entre a medicina científica e as práticas populares. Aqui se encontra ressaltada a sua própria posição ambígua, marcada pelas dificuldades de ascensão social à classe médica, assumindo uma posição inferior em relação a outros médicos oriundos de classes mais privilegiadas. Em termos práticos, isto significava a cobrança de preços populares para as consultas e $o$ atendimento circunscrito aos limites do seu bairro de origem. É importante ressaltar que dadas as condições de familiaridade com sua clientela, o médico popular, ou particular, como também era conhecido, costumava compreender melhor as referências e práticas populares de cuidado (incluindo explicações mágico-religiosas), bem como fazer adaptações e facilitar o acesso a exames e medicamentos (LOYOLA, 1984).

Para a autora, desta posição ambígua e contingente dos médicos populares, decorre a sua influência e legitimidade perante a clientela:

Propriedades e disposições particulares que os levam a praticar uma medicina orientada socialmente com tendência a remediar as desigualdades em matéria de saúde e de cuidados médicos, o que lhes permite ao mesmo tempo resolver as contradições criadas por esta sua posição limítrofe ou periférica, de intermediários entre classes sociais. (LOYOLA, 1984, p. 27).

Cumpre destacar nas análises prestadas por Loyola (1984), não apenas a preferência dos moradores do bairro pelos médicos populares, como também a prática de uma medicina familiar, que se realizava a partir do compartilhamento de receitas de família, trocas com a vizinhança, cultivo de ervas e remédios caseiros, que eram armazenados e compartilhados, como também o compartilhamento de orientações e receitas médicas já conhecidas pelos moradores. Conforme observou Loyola, a procura por um especialista de cura, mesmo o médico popular, só se dava depois de esgotadas as tentativas de cuidados no âmbito familiar-comunitário.

É preciso ter em mente que os moradores do bairro, quando doentes, se tratam primeiro por conta própria e só recorrem aos diversos especialistas da cura depois de esgotarem todos os recursos terapêuticos

familiares. Estes resultam, basicamente, de uma experiência acumulada pela família - e/ou pelos vizinhos - durante doenças anteriores, quando puderem medir a eficácia tanto de uma prática propriamente familiar, como da prática dos especialistas consultados nas ocasiões. $O$ conhecimento médico familiar resulta, assim, de uma experiência prática na qual se associam, inseparavelmente, receitas de comadres, remédios caseiros, conselhos de vizinhos, diagnósticos e medicamentos dos especialistas. (LOYOLA, 1984, p.

125-126).

Reservadas as análises das consequências favoráveis ou desfavoráveis de tais condutas, recorta-se aqui - aspecto comunitário-solidário de tais práticas coletivas de cuidado observadas em Nova Iguaçu e, particularmente, no bairro de Santa Rita, resumido nas palavras de uma das moradoras entrevistadas "Se houver necessidade, corre como um formigueiro, um lutando com o outro" (idem, p. 125). Deste fazer comunitário, refletido na combinação de diferentes orientações nos cuidados com a saúde, a autora apresenta um cenário de práticas médicas modernas e tradicionais coexistentes, ainda que em uma relação evidentemente desigual.

A coexistência de referências é um dos aspectos notoriamente destacados nos estudos pós-coloniais de Homi Bhabha (1998), particularmente no que diz respeito à definição dos entre-lugares, termo cunhado pelo autor, que designa "uma temporalidade de construção e contradição social que é iterativa e intersticial; uma intersubjetividade insurgente que é interdisciplinar" (BHABHA, 1998, p. 315, grifos do autor). Para o autor, expressões minoritárias são fortalecidas não exatamente pela persistência da tradição, mas pelas possibilidades das práticas tradicionais se reinscreverem nas condições do presente. A dinâmica dos entre-lugares sugere exatamente uma ação inaugural que é fruto de um encontro, da mútua intrusão de sistemas de referência muitas vezes distintos, ligados e fundidos em práticas atuais, num contexto atual de produção de sentidos para um determinado grupo.

Embora muitos pesquisadores tenham ajudado na compreensão de que a ciência médica jamais teria conseguido extinguir as demais práticas de cuidado e cura (LOYOLA, 1984; LAPLANTINE; RABEYRON, 
1991; QUINTANA, 1999, entre outros), é preciso marcar alguns aspectos importantes neste conjunto de tensões. A rejeição e a desqualificação dos meios de cuidado e cura dos terapeutas populares, práticas enraizadas no ethos e visão de mundo de um Brasil nativo, fazem coro com a progressão da medicina científica ascendente.

À prosperidade do positivismo oitocentista no estudo e controle da morbidade em contextos urbanos, razões amplamente associadas à cientificidade ascendente da medicina moderna (FOUCAULT, 1993), soma-se, no século $X X$, uma preocupação maior na vigilância das fronteiras entre aquilo que é e o que não é científico.

Para a análise aqui empreendida, cabe observar que este tipo de reação da medicina científica às práticas não científicas inaugura uma divisão entre, de um lado, os saberes médicos e as modernas técnicas cientificamente amparadas e, do outro, saberes difusos, amplamente referenciados em tradições culturais e sistemas de cura mágicosreligiosos, práticas populares transmitidas entre gerações, medicinas tradicionais centenárias, milenares, etc. (LOYOLA, 1984; LAPLANTINE; RABEYRON, 1991; QUINTANA, 1999, entre outros). Eis uma diversidade comprimida, enfim, sob a inscrição do não-científico ou não-médico.

Destarte, a cisão entre as práticas de cuidado sob o crivo da cientificidade, parece excluir a dimensão ritual de toda prática do cuidado. Conforme analisam Laplantine e Rabeyron (1991, p. 34), "toda técnica, ainda que medicinal, também tem uma dimensão ritual, e os rituais podem conter em si mesmos uma eficácia". Nesta mesma linha de pensamento, lembra Carrara (1994), há uma intrínseca relação entre prática e discurso médico que, por seu turno, é permeado por construções simbólicas que logram dada eficácia:

O que os cientistas fazem em seus laboratórios (o que nós mesmos fazemos) não é certamente, como quer o cientismo vulgar, descobrir fenômenos que desde sempre estavam lá a sua espera. Eles constroem símbolos a partir de certos materiais. E a relação entre os símbolos e a realidade que buscam exprimir não é nem totalmente aleatória, nem totalmente arbitrária. A questão certamente não é saber se o 'vírus' existe lá antes de qualquer olhar curioso, mas se, a partir do momento em que ele se transforma em símbolo da doença com a qual ele foi construído, ele tem poder explicativo e é eficiente para orientar uma intervenção eficaz. Ele é um artefato biológico, foi feito pelos cientistas como todos os outros artefatos, da roda ao computador. (CARRARA, 1994, p. 43).

Ao propor a categoria "racionalidades médicas", Luz (1988) defende a ideia de que a medicina científica é um discurso cultural e socialmente construído como qualquer outro. Assim, afasta referenciais de análise que tomem o científico como uma verdade universal e absoluta ou como medida a partir da qual todas as racionalidades deveriam ser reconhecidas ou não. A definição da categoria "racionalidades médicas" permitiu o estudo comparativo entre diferentes sistemas de cuidado, evitando cair em juízos de valor éticos ou epistemológicos. As críticas à medicina científica, pautada na análise de modelos e racionalidades abrem importantes precedentes para a investigação de práticas de cuidado distintas. Definidas atualmente como práticas integrativas, é possível observar movimentos de convergência em torno de categorias como alternativas ou como complementares às práticas médicas, em uma relação de exterioridade e de fronteira.

Entendemos que a partir da "ecologia de saberes", como definida em Santos (2002), é possível ampliar - espectro da compreensão das práticas, ora tomadas como concorrentes, ora complementares, especialmente à medida que o autor reconhece no crivo científico o "pensamento abissal" (idem) que exclui $\circ$ que não é visível sob uma determinada ótica. Como defende, "a característica fundamental do pensamento abissal é a impossibilidade da copresença dos dois lados da linha" (SANTOS, 2007, p.4)

Nesta medida, nos interrogamos: a desabilitação das práticas populares de cura, a partir de mecanismos de desqualificação e de hostilidade ao não-científico, até o ponto da invisibilidade, pode explicar em parte estas "não existências" (SANTOS, 2002) temporárias que, latentes, podem, em determinado momento e a partir de circunstâncias favoráveis, reaparecer? 


\section{Às margens da Ciência}

Embora a divisão entre práticas de cuidado científicas e não científicas seja problemática, especialmente em função da diversidade comprimida na genérica categoria do "não-científico", a força de certos fenômenos sociais deve ser considerada ao tomarmos as práticas de cuidado não-científicas como um domínio possível de construção e prática do cuidado.

Os "curandeiros modernos" (LAPLANTINE; RABEYRON, 1991) ou "alquimistas da cura" (TAVARES, 2012) - ou, como em grande parte se definem: terapeutas - são abordados, na contemporaneidade, a partir de referências e análises de fenômenos sociais cuja força se revela na concretude de alguns elementos, dentre os quais: - a existência de associações, redes (LAPLANTINE; RABEYRON, 1991) e/ou sindicatos de terapeutas, que atestam níveis diferenciados de organização profissional, incluindo a proteção dos direitos de atuação;

- a organização de conferências locais e internacionais em que novos terapeutas e/ou trabalhos são apresentados, gerando um fluxo de publicações e produtos especializados que alimentam a "rede terapêutica" (TAVARES, 2012) ou "circuitos alternativos" (MALUF, 1996);

- a organização de "eventos" e "encontros" entre terapeutas e clientes, de caráter formativo e vivencial, cujo espectro sinaliza o cultivo de uma cultura de "Nova Era" (AMARAL, 2000);

- a existência de imprensa e meios de comunicação especializados (LAPLANTINE; RABEYRON, 1991); e

- $\quad$ progresso de um mercado dedicado a este segmento (TAVARES, 2012).

Tavares (2012), em seu estudo sobre circuitos urbanos de práticas terapêuticas integrativas, ressalta $\circ$ interesse da classe média na procura por estas modalidades de tratamento. A especialização terapêutica, com a emergência de um campo profissional, é aqui apontada como fenômeno de crescente influência, corroborando com a criação de nichos de mercado especializados. Portanto, a autora trabalha com a noção de rede terapêutica alternativa, composta por terapeutas, clientes, terapias, encontros, cursos profissionalizantes, produtos especializados, etc.

O provimento de tratamentos naturais e produtos que, grosso modo, marcam um novo estilo de vida, aciona a corrida no campo profissional pela qualificação e habilitação. A antiga disputa de espaço, consideradas as devidas proporções, entre uma medicina emergente e uma medicina popular ou, ainda, entre uma medicina científica e uma medicina tradicional se reproduz, em particular, quando a conduta da medicina se mostra mais comprometida com uma disputa de mercado, distanciando-se, em igual proporção, de suas bases humanistas, outrora comprometidas em propor soluções para as mazelas sociais (MARTINS, 2003).

Se, por um lado, os autores debruçados sobre as práticas de cuidado externas à ciência médica reconhecem que o prestígio dos terapeutas está pautado na confiança e reconhecimento por parte do grupo social, por outro, se observará o desprestígio conferido a estas práticas que, por não responderem aos critérios científicos, são colocadas sob o rótulo comum de charlatanismo, crendice, ineficácia, ou seja, um "retorno ao obscurantismo que a ordem médica biologizante pensava ter vencido". (LAPLANTINE; RABEYRON, 1991, p. 24).

Reciprocamente, terapeutas alternativos elaboram um conjunto de críticas às práticas médicas, a partir das quais defendem o seu lugar de atuação no universo dos cuidados. Baseado no estudo de diversos autores debruçados sobre o tema (AMARAL, 2000; ANDRADE, 2006; LAPLANTINE; RABEYRON, 1991; MALUF, 1996; MARTINS, 2003; TAVARES, 2012; entre outros) resumimos no quadro abaixo algumas das críticas formuladas à ciência médica, situando ao lado o contraponto apresentado pelos terapeutas alternativos: 
Quadro 1. Críticas à ciência médica e contrapontos das terapias integrativas

\begin{tabular}{|c|c|}
\hline Crítica à medicina científica & Contraponto apresentado pelos terapeutas \\
\hline $\begin{array}{l}\text { "Desumanizaçâo da medicina" e prática de uma } \\
\text { "medicina dos órgãos" (Martins, 2003) } \\
\text { "O doente visto como objeto, o médico como } \\
\text { mecânico, a doença como avaria e o hospital } \\
\text { como oficina de consertos" (Laplantine; } \\
\text { Rabeyron, 1991) }\end{array}$ & $\begin{array}{c}\text { Visão integral do ser humano, } \\
\text { acolhimento, } \\
\text { escuta, afetividade. } \\
\text { "suplementação psicológica e social" (Laplantine; } \\
\text { Rabeyron, 1991) }\end{array}$ \\
\hline $\begin{array}{c}\text { Centralidade na doença que, via de regra, é } \\
\text { concebida como um ataque de um agente } \\
\text { externo ao corpo, que deve ser atacado e } \\
\text { vencido }\end{array}$ & $\begin{array}{c}\text { Visão da doença a partir da noção de equilíbrio e } \\
\text { desequilíbrio. } \\
\text { Concepção da "energia" como categoria } \\
\text { fundamental (Tavares, 2012), que auxiliará na } \\
\text { compreensão destes desequilibrios, bem como dos } \\
\text { bloqueios que geram doenças }\end{array}$ \\
\hline $\begin{array}{c}\text { Tratamentos invasivos e destrutivos, que } \\
\text { provocam males secundários e geram uma } \\
\text { cadeia de doenças }\end{array}$ & $\begin{array}{l}\text { Tratamentos naturais, de fortalecimento e } \\
\text { potencializaçấo dos mecanismos próprios de } \\
\text { defesa de cada um }\end{array}$ \\
\hline $\begin{array}{l}\text { Abordagem fechada em seus sistemas de } \\
\text { tratamento. Aversão ou desconhecimento/ } \\
\text { desprezo pelo que não é científico }\end{array}$ & $\begin{array}{l}\text { Reconhecimento da necessidade de } \\
\text { encaminhamento para os casos mais graves, que } \\
\text { necessitam de intervençấo médica }\end{array}$ \\
\hline
\end{tabular}

Mesmo investindo em diferenciações entre sistemas de referências, e de certa forma aprofundando aversões, é apenas em função da presença de pontos de contato entre referências tomadas como concorrentes ou divergentes que se formam zonas de "perturbação" e de "contestação", potencialmente revisionários, e portanto disparadores de transformações e afetações mútuas. Como relembra Bhabha (1998), estas zonas, compreendidas como entre-lugares, podem ser tanto consensuais quanto conflituosos.

A aceitação de terapias integrativas nunca foi consensual no meio médico, porém, aos poucos, uma significativa parcela dos profissionais foi aderindo a estas práticas e, via de regra, construindo caminhos para que se tornassem especialidade reivindicada pela própria medicina, como no caso da homeopatia. A consequente desabilitação dos profissionais não médicos, como foi o caso dos homeopatas populares, e, na atualidade, a ameaça que paira sobre os profissionais de acupuntura, habilitados pelos métodos de formação da Medicina Tradicional Chinesa, é uma dos temas mais tensos da área de saúde. No Brasil, muitos embates decorreram do projeto de lei conhecido como ato médico, sancionado pela presidenta Dilma Rousseff, em julho do ano de 2013. Dentre os vetos anunciados, o mais importante e que teve maior repercussão, foi o que impediu que a formulação de diagnóstico de doenças, bem como as práticas terapêuticas não invasivas fossem consideradas competências exclusivamente médicas, ponto defendido fervorosamente pelo ato médico, com anuência majoritária da categoria.
À insistência na produção de invisibilidades ou "inexistências", que no sentido empregado por Santos, consiste em "não existir sob qualquer forma de ser relevante ou compreensível" (SANTOS, 2007, p.4), opõe-se a afirmação de práticas e saberes a partir de uma realocação de signos vivificada em condições presentes, que antecipam a sua identificação ou reconhecimento. Os múltiplos arranjos e rearranjos de saberes em torno de práticas de cuidado, como revelados amplamente em muitas das citadas pesquisas, já indicam uma arqueologia de saberes, que, de "esquecidos" ou "invisíveis" tornam-se amálgama para novos usos e práticas. A seguir, pretendemos avançar mais um pouco no sentido de compreender esta polifonia em torno das práticas não científicas de cuidado e cura: medicinas paralelas, brandas, naturais, alternativas, holísticas, complementares, integrativas, entre outras.

\section{Do Alternativo ao Integrativo}

Uma primeira reação social mais proeminente e que, necessariamente, tocou a questão dos cuidados, visto que propunha uma revirada geral em todos os padrões sociais, está comumente associada, na literatura, aos movimentos de contracultura nos anos 1960 e 1970 (SOUZA e LUZ, 2009; NOGUEIRA, 2010; LAPLANTINE; RABEYRON, 1991). A proposta, como se sabe, era a de uma grande abertura para a experimentação de novos modos de vida, outros padrões de crença, novas formas de se cuidar, de lidar com o corpo, com a saúde, com a espiritualidade, tudo isto misturado a questionamentos políticos e à 
atmosfera de revolução na qual tudo passava a ser questionado, conforme Laplantine e Rabeyron, vinculada a uma série de "recusas", dentre as quais, "ao racionalismo científico e técnico e mitologias do progresso, à cultura intelectual, revalorizando o corpo, a cultura elitista, revalorizando o simples, a sociedade do objeto e da objetividade, valorizando o humano e as relações" (1991, p. 29).

Neste contexto, a receptividade a outras culturas também foi um fato marcante. Como destacam Souza e Luz:

Naquele momento, uma juventude revolucionária partia em busca de novas soluções terapêuticas, utilizando tais práticas não apenas como terapias, mas como símbolos de uma 'revolução cultural'. Uma parte dessa 'estratégia revolucionária' foi a importação de sistemas exógenos de crença e orientações filosóficas, geralmente orientais, que serviram de fundamento para a construção de um corpo ideológico de orientações práticas. (SOUZA e LUZ, 2009, p. 394).

Muitos destes questionamentos também se expressaram através de movimentos pacíficos cujo emblema "paz e amor" era a expressão mais eloquente. $O$ gosto por um estilo de vida mais natural e pela compreensão do corpo também como uma totalidade, assim como a liberação sexual, o gosto de fazer do corpo o que bem entender, especialmente no tocante às mulheres (MARTINS, 1999), foram algumas das formas de insubordinação experimentadas.

Neste sentido, como defendido por Souza e Luz (2009), os movimentos da contracultura deram um primeiro impulso para a difusão de sistemas e terapêuticas baseadas em racionalidades vitalistas, aquelas que tendem a oferecer uma perspectiva mais integradora diante do paciente, pois a prática clínica exige um levantamento aprofundado de sua história de vida, compreendendo a doença de uma maneira bem mais ampla que o tratamento do sintoma. A rebeldia de cuidar-se e tratar-se por meios anticonvencionais logrou, em contrapartida, um maior conhecimento e aceitação social das terapias alternativas, expressão que talvez melhor sintetize o espírito da época.

Conforme Martins (1999), as consideradas terapias alternativas estariam pautadas em outros parâmetros e reivindicavam "cientificidade" de maneira distinta dos critérios adotados pelos sistemas de cura estabelecidos na medicina científica. Os sistemas de cura que caracterizam as terapias alternativas se inspiravam em "tradições orientais e ocidentais espiritualistas, bioquímicas e psicológicas". Destaca o autor:

De fato a análise do sistema terapêutico alternativo permite concluir que elas resultam de um processo de aproximação de medicinas tradicionais e populares, orientais e ocidentais. Neste sentido, a rápida emergência das Terapias Alternativas, nos últimos anos, responde a diferentes demandas que buscam respostas simultâneas para questões de ordem física, psicológica e espiritual. (MARTINS, 1999, p. 41).

Ainda conforme Martins, as transformações no "imaginário do corpo" trouxeram grandes consequências para o conjunto das práticas de saúde. Historicamente utilizado como instrumento de trabalho, o corpo ganha um sentido vinculado à "instituição de uma vontade de poder", recolocando a questão da autonomia e da busca pessoal (1999, p. 36). Este corpo liberto de determinismos meiofim estaria apto a se utilizar do conhecimento tradicional, de tecnologias e saberes milenares sem, contudo, retornar ao ponto específico da tradição, em termos de organização social e/ou psíquica. Como ressalta Amaral, estas práticas constituiriam:

a possibilidade de transformar, estilizar, desarranjar ou rearranjar elementos de tradições já existentes e fazer desses elementos metáforas que expressem performaticamente uma determinada visão, em destaque em um determinado momento, e segundo determinados objetivos. Não mais circunscritos à sua comunidade de origem ou a seus grupos 'naturais', esses elementos religiosos, espirituais e místicos - rituais

e mágicos - são recobertos de uma alta diversidade de significados e usados para uma variedade de propósitos. (1999, p. 47).

Inicialmente rejeitadas, estas práticas foram conquistando alguns adeptos no campo da saúde. $O$ interesse dos profissionais da área médica também já sinalizava algumas mudanças nas quais se observará uma maior busca pela profissionalização e pela institucionalização (SOUZA e LUZ, 2009). Não à toa, a homeopatia é convertida em especialização médica, no Brasil, no ano de 1980. 
Consequentemente, são desabilitados todos homeopatas populares que até então atuavam.

Na década de 1990, um novo fenômeno reacende o interesse pelas terapias integrativas. A motivação, então, era o movimento que se tornou conhecido como Nova Era, conforme Tavares (1999), fenômeno espiritualizante que congrega sabres religiosos, filosóficos, místicos e esotéricos numa proposta de prática terapêutica. A expressão holismo, em referência ao todo, ao inteiro ou ao total (LALANDE, 1999) seria a que melhor se aplicava ao sentido dado a estas práticas, que passavam então a ser amplamente conhecidas como Terapias Holísticas.

Os movimentos de Nova Era se diferenciavam particularmente dos movimentos de contracultura, por estarem mais centrados em uma perspectiva do sujeito atrelada à questão das buscas pessoais e ao aperfeiçoamento do ser individual (TAVARES, 2012), diante de um mundo definitivamente fragmentado. Apoiada em María Carozzi, Tavares (2012) analisa o fenômeno tal como uma espécie de "sacralização da autonomia", que confere uma "chave transformadora" diante das instituições do cuidado, das religiões institucionalizadas, de si mesmo, dos outros, do próprio corpo, enfim.

A ideia de uma individualidade que se trabalha em afinação com os princípios de uma nova era aciona a busca por serviços terapêuticos e o holismo se torna a senha de um ideal de ser. Também se observa uma ampliação na prestação de serviços e uma busca de delimitação de um campo de atuação profissional com a multiplicação de terapeutas. É interessante notar a forma como a expressão holista auxiliará na identificação destes profissionais e dos serviços que oferecem.

No contexto das práticas integrativas, o termo passa a ser evocado como uma referência a partir da qual terapeutas e práticas são identificadas, uma espécie de abrigo de sentido que, além de dar significados às práticas, produz distinções em relação àquilo com o que não quer se confundir. Assim, ao mesmo tempo em que unifica, delimita um campo de atuação profissional (TAVARES, 1999).

Conforme Tavares (2012), "o conteúdo de sentido genérico desse holismo, bem como sua maior ou menor explicitação no discurso, constituem uma indicação de que os terapeutas não-médicos reelaboram esse referencial de formas variadas" (TAVARES, 2012 , p.39). Esta variação e certa nebulosidade na apropriação da categoria práticas holísticas pode ser explicada, conforme Tavares (2012), pela "necessidade de marcar alguns traços e minimizar outros, em função de uma ou outra perspectiva com a qual se deseja estabelecer relações de proximidade ou da qual se pretende distinguir" (TAVARES, 2012, p.35). A autora identifica dois modeloslimite de legitimidade terapêutica: o referencial de ordem científica e o referencial mágico-religioso. O primeiro sugere certa analogia em relação ao campo da medicina científica, em que se procura comprovar a eficácia de tais práticas, enquanto o segundo tem uma maior conexão com a dimensão espiritual. (TAVARES, 1999).

Apesar de o trabalho terapêutico propor um bem estar e mesmo a cura a partir de um conjunto específico de intervenções e procedimentos técnicos, existe, conforme Tavares, uma alusão a uma experiência mais profunda, ampla e difusa, com referências à totalização e à saúde de maneira global. Como consequência desse projeto mais amplo, surge, frequentemente, uma crítica operacional à medicina oficial, considerada como unilateral e empobrecedora e cuja abordagem de corpo consistiria em um verdadeiro impedimento para este bem estar integral (TAVARES, 1999). Uma menor pressão para a lealdade à "própria organização e à ortodoxia disciplinária" (CAROZZI, 1999, p.11) e uma circulação de conhecimentos e saberes dispersos, reunidos ocasionalmente ou colocados em ação a partir de uma combinação de saberes (ainda que seja em função de uma condição de complementaridade à biomedicina), são novidades atribuídas às práticas terapêuticas circunscritas sob o espectro do holismo, já anunciado como o tom da Nova Era.

\section{Algumas Conclusões}

O aumento na aceitação de sistemas terapêuticos alternativos de cuidado é consoante com o momento de preocupação geral com as formas de gestão da vida: preocupações que se acumulam, emaranhamentos de problemas, tais como a produção 
de doenças, em que a iatrogenia, a toxidade e condição patológica de estresse são flagrantes e indubitáveis; a finitude de recursos naturais, e a nossa própria finitude em perspectiva, entre outras. Diversas vias de cuidados têm despontado como mais eficientes que as vias convencionais no tratamento de algumas patologias e pode-se dizer que os resultados alcançados através destas buscas, para muitas pessoas, significou um ganho tão maior que o critério da cientificidade (do qual a ciência médica sempre se valeu), muitas vezes, perdeu a sua força explicativa/persuasiva. Se concordarmos com Schraiber (2010), quando afirma que tudo o que um paciente espera de seu médico é que ele dê um jeito de reduzir o seu sofrimento, em termos pragmáticos, é compreensível que os caminhos alternativos à ciência passem a ser procurados em situações de incerteza vivenciadas na relação médico-paciente.

As consequências desta abertura e da procura da sociedade por terapias alternativas/holísticas/ complementares/ integrativas são muitas. Desde reações negativas, como a de uma medicina ávida por transformar algumas destas práticas em especialidade/ exclusividade médica (o que acirra, ainda mais, as disputas de poder, ao tentar submeter todo e qualquer tipo de tratamento ao crivo de um médico - psicologia, fisioterapia, enfermagem, etc.), até as reações um tanto mais positivas, como a aceitação/aprovação destas terapias, ainda que na condição de complementares à prática médica. Este foi, sem dúvida, o caminho mais cordial, no Brasil, para o reconhecimento e a incorporação no Sistema Único de Saúde (SUS) das então Práticas Integrativas em Saúde (PICS) (BRASIL, 2006). Além disto, a publicação da Política Nacional de Práticas Integrativas e Complementares no SUS (PNPICS) também buscou atender às diretrizes e recomendações de várias Conferências Nacionais de Saúde (CNS's) e às recomendações da Organização Mundial da Saúde (OMS).

A forma própria de denominá-las "práticas integrativas" é resultante de uma ampla discussão e de um trabalho já iniciado há algumas décadas por diferentes profissionais e pesquisadores. Em lugar de "alternativas" ou "complementares" e mesmo "holísticas", expressões consideradas muitas vezes herméticas, ambíguas ou subalternas (alternativas e complementares, por exemplo, pressupõem que algo está no centro), a denominação integrativa traz a perspectiva da inclusão, um passo importante no sentido da recuperação daquilo que foi rompido em função da posição unilateral da medicina científica. Destaca-se, ainda, o papel do movimento em prol da reforma sanitária no Brasil que, paralelamente, contribuiu para estas novas concepções acerca das terapêuticas distintas da medicina científica. Muitas das propostas debatidas e formuladas no momento de mobilização social intensa em favor da democratização, como vivido no Brasil pós-ditadura, foram incorporados na Constituição Brasileira promulgada em 1988 (CF/88) considerada um grande marco do movimento em torno da reforma sanitária no Brasil, que se estende até a atualidade, apoiando o debate e a avaliação das políticas de Saúde em torno de questões tais como o direito à Saúde, a inclusão social e o acesso do usuário, a participação popular nas decisões, em suma, a integralidade das práticas em saúde enquanto princípio constitucional.

É necessário compreender a influência desses movimentos em favor da integralidade na Saúde no reconhecimento e incorporação das práticas integrativas ao sistema de saúde oficial, passo extremamente importante para a sua legitimação junto à sociedade. De fato, a PNPIC, em vigência desde 0 ano de 2006, prometeu um horizonte mais próspero e de colaboração entre as diversas práticas de atenção à saúde. De incômodas (no sentido das tensões e disputas geradas) ou herméticas (no sentido de pertencimento a uma Nova Era) a integradas (ou talvez integradoras, uma vez que facilitam a mobilidade de papéis, exigindo, até, uma posição de engajamento e disposição para o aperfeiçoamento pessoal do cliente), um vasto e sinuoso caminho percorrido, com muitos interesses em jogo e, mais dramaticamente, a questão da saúde e doença, vida e morte, elementos que acirram esta discussão. 


\section{AGRADECIMENTOS}

Este trabalho contou com o apoio da Fundação de Amparo à Pesquisa do Estado da Bahia - FAPESB.

\section{CONFLITOS DE INTERESSES}

Nenhum conflito financeiro, legal ou político envolvendo terceiros (governo, empresas e fundações privadas, etc.) foi declarado para nenhum aspecto do trabalho submetido (incluindo mas não limitandose a subvenções e financiamentos, conselho consultivo, desenho de estudo, preparação de manuscrito, análise estatística, etc).

\section{REFERÊNCIAS}

Amaral, L. (2000). Carnaval da alma: comunidade, essência e sincretismo na nova era. Petrópolis, RJ: Vozes.

Andrade, J.T. (2006). Medicina alternativa e complementar: experiência, corporeidade e transformação. Salvador: UFBA; Fortaleza: EdUECE.

Bhabha, H.K. (1998). O local da cultura. Belo Horizonte: ED. UFMG.

Carozzi, M. (Org.). (1999). A nova era no Mercosul. Petrópolis, RJ: Vozes.

Carrara, S. (1994). Entre cientistas e bruxos: ensaios sobre dilemas e perspectivas da análise antropológica da doença. In: Alves, P.C; Minayo, M.C.S. Saúde e doença: um olhar antropológico (p. 33-45). Rio de Janeiro: Fiocruz.

Brasil. Ministério da Saúde. Secretaria de Atenção à Saúde. (2006). Departamento de Atenção Básica. Política Nacional de Práticas Integrativas e Complementares no SUS - PNPIC-SUS. Ministério da Saúde, Secretaria de Atenção à Saúde, Departamento de Atenção Básica. - Brasília.

Foucault, M. (1993). Microfísica do poder. Rio de Janeiro: Graal.

Lalande, André. (1999). Dicionário técnico e crítico da filosofia. São Paulo: Martins Fontes.

Laplantine, F; Rabeyron, P.L. (1991). Medicinas paralelas. São Paulo: Brasiliense.

Loyola, M.A. (1984). Médicos e curandeiros: conflito social e saúde. São Paulo: Difel.

Luz, M.T. (1998). Natural, racional, social: razão médica e racionalidade científica moderna. Rio de Janeiro: Campus.

Maluf, S.W. (1996). Des enfants du Verseau au pays des terreiros: les cultures thérapeutiques et spirituelles alternatives au Sud du Brésil. (Tese Doutorado em Ciências Sociais) - École des Hautes Études em Sciences Sociales, Paris.

Martins, P.H. (1999). O paraíso, o Tao e o dilema espiritual do Ocidente: passagem do antropocentrismo moderno para - cosmocentrismo pós-moderno. In Siqueira, D.E. (org.) Sociedade e Estado, XIV, 19-44, Universidade de Brasília, Brasília.

Martins, P.H. (2003). Contra a desumanização da medicina: crítica sociológica das práticas médicas modernas. Petrópolis, RJ: Vozes.

Montagner, M.A. Sociologia médica, sociologia da saúde ou medicina social? um escorço comparativo entre França e Brasil. Saude soc., 17(2), 193-210. doi: 10.1590/ S0104-12902008000200018

Nogueira, M.I. Racionalidades Médicas e formação em saúde: um caminho para a integralidade. In: Pinheiro, Roseni; Silva JR., Aluisio Gomes da (Org.). Por uma sociedade cuidadora. Rio de Janeiro: CEPESC; IMS/UERJ; ABRASCO, 2010

Pimenta, T.S. Barbeiros: sangradores e curandeiros no Brasil (1808-28). (1998). Hist. ciênc. saúde Manguinhos, 5(2), 349-374. doi: 10.1590/S0104$\underline{59701998000200005}$

Quintana, A.M. (1999). A ciência da benzedura: mau olhado, simpatias e uma pitada de psicanálise. São Paulo: EDUSC.

Santos, B.S. (2002). Para uma sociologia das ausências e uma sociologia das emergências. Revista Crítica de Ciências Sociais, 63, 237-280.

Santos, B.S. (2007). Para além do pensamento abissal: das linhas globais a uma ecologia de saberes. Novos estud. - CEBRAP, 79. doi: 10.1590/S010133002007000300004

Schraiber, L.B. (2010). Racionalidade biomédica e transformações históricas da prática médica ao longo do século $X X$ : breves apontamentos para a reflexão crítica. In: Pinheiro R; Silva J, Aluisio Gomes (Org.). Projeto Integralidade em Saúde _ 10 anos: por uma sociedade cuidadora. Rio de Janeiro: CepescIMSUERJ-Abrasco, 1, 1 15-128.

Souza, E.F.A.A.; Luz, M.T. (2009). Bases socioculturais das 
práticas terapêuticas alternativas. História, Ciências, Saúde - Manguinhos, 16(2), 393-405. doi: 10.1590/ $\underline{\text { s0104-59702009000200007 }}$

Tavares, F.R.G. (1999). Ascensão e profissionalização da terapêutica alternativa no Rio de Janeiro (anos 8090). Physis - Revista de Saúde Coletiva, 9(2), 75-98. doi: $10.1590 /$ S0103-73311999000200005

Tavares, F.R.G. (2012). Alquimistas da cura: a rede terapêutica alternativa em contextos urbanos. Salvador: EDUFBA. 